continuance than before. The part becoming a still greater source of irritation than ever, and the general bealth fast breaking up, Mr. Key proposed amputation, to which the man readily consented.

The operation by the circular incision was performed last Tuesday. A good deal of blood was lost at the time, and there was slight hemorrhaye afterwaris ; but, up to the present period, (Monday,) the man is doing well.

FATAL TERMINATION OF MR. MORGAN's CASE OF FUNGOIN DISEASE.

We regret to state that Mr. Morgan's singularly bold operation, in the removal of an immense fungoid tumour, has proved unsuccessful. The patient sunk on the tenth day, from diarrhoa.

It will be recollected that, at the conclusion of our last report, it was stated the woman was doing well, with the exception of slight diarrhoxa, for which chalk mixture, with aromatic confection, was prescribed. On the evening of the same day, the relaxation of the bowels increased, and continued until death, in spite of various means that were employed. If we may credit the testimony of the nurse, the poor woman "persisted" in eating ripe fruit, and taking large quantities of subacid àrinks.*

\section{Post-mortem Eramination.}

The body exhibited but slight traces of disease. There were a few small tubercles on the pleuritic surface of each lung. Adhesion lad taken place throughout nearly the whole extent of the wound; bat, in one small spot, the fungus showed a disposition to sprout.

\section{WINCHESTER COUNTY HOSPITAL.}

DELIRTUM TRFMENS, FOILONTNG FRACTURE OF THE THIGH, SUCCESSFUILY TREATED BY VFNESHCTION AND OPIYM.

Communicated by R. Cormin, Exq., Flouse

Wm. Brewer, wat. 34, was admitted into the Hospital on the 1.14 day of July, with an oblique fracture of the right tubia, about midway between the knee and ancle joint, attended with considerable contusion and

* We should be glad to know whose duty it was to prevent the patient from taking such things, if considered improper. Why are women aliowed to go though the wards and hawk fiuit, which, for the most part, is the very refuse of the Borough marlet? ED. I. swelling. The fracture was reduced, and the leg placed on its outer sicle on a splint, with the knee bent; an evaporating lotion was constantly applied, and aperient medicines were given. After the expiration of eleven days, the limb was in a proper state for the application of bandinges and splints. which were arljusted in the usual manner, and the patient went on exceedingly well till the 7 th of this month, when he was moldenly attacked, about five o'clock in the afternoon, with furious delirium. He sprang: from his bed, totally disregarding his fractured leg, and would have attempted walk ing across the Ward, had he not fortunately been prevented by the other patients; and on again being placed in his bed, his exertions to quit it were so violent that two men were necessary to restrain him. He was exceedingly loquacious, talking in the most incolerent mamner about drinking, (to which he was particularly addicted,) huntin $₫$, fishting, \&c. and irequently attempting different comic songs, from which he would only desist on being promised some drink. His countenance was thushed and animated; eyes bright and quick, with the pupits rather contracted; pulse frequent, full and hard; tongue slightly brown and dry; his thirst was excessive; slin dry and very hot; and, notwithstanding all these symptoms, he complained of no pain. He was bled to 20 ounces, and a drachm of the tinct. opii was given immediately afterwards. Seven o'clock P.M., continuing just the same, he was bled again to the same quantity, and three grains of opium, with ten grains of calomel, were given, and an evaporating lotion was applied to his head. 'Ten o'clock, 1' ${ }_{1}$., there being no alteration in his symptoms, the bleeding was again repeated, and three grains more of opium were immediately giren; and, after three hours, he was directed to take one grain of opium every hour.

Aug. 8, eight o'clock, A.Mr. He has been the whole of the night either talling, singing, or holloing, and occasionally attempred getting out of bed. His tongue is moist and clean, and his pulse is sotter and not so quick. Three grains of opium were given, and the tvaporating lotion continued. Eleren o'clock a.m. Continuing in every respect the same, and his bowels not being relieved, a common injection was given, which operated well. 'ithree o'clock P. M. He lias been in a trangril state for the last hour, occasionally dozing, but has just re. lapsed into his furmer condition, when it was determined on giring $n: x l$. of the tinc. ture of opium in a common cnema, which was directed to be repeated in three hours, and the evaporatiug lotion to be continued.

Aug. 9, eight o'clock A.a. Has been tolerably quiet ever since an hour after the 
last report, and is quite sensible this morn. ing, complaining of great pain in his head, which was relieved by the application of a blister to the nape of the neck, and the exhibition of a calomel purge. From that time he has been gradually improving, with the exception of one slight paroxysm, which was speedily relieved by the enema, with tincture of opium, and he is now quite convalescent.

Remarlss.-This case appears very analogous to one that was reported in your valuable Journal a little time since, by Baron Dupuytren, in which he states that all kinds of sedatives, and bleeding ad deliquium, had proved unsuccessful, and that the only means of cure, were injections of small doses of opium in the rectum; but from this case, together with the observations made by $M r$. W. Wickham, (under whose care this man was placed,) I should be induced to think that the bleeding tended as much as the opium, (which was in large doses,) towards this man's recovery. Mr. Wickham observed that he had witnessed five cases of the same disease, four of which had unfortunately sunk under the attack, within five or six days from their commence. ment. In these the purely antiphlogistic system had been adopted. That in the fifth case, which was in a man of great power of body and strength of constitution, he had succeeded in curing the disease by copious bleedings, and large doses of opium. This person was bled to 40 ounces at first, and afterwards to 20 , at two different times. Each bleeding was ad deliquium, and the opium was given immediately afterwards. He considered the disease to be one rather of irritation than an inflammatory character; that, in fact, the sensorium was suffering from preternatural excitement, and that, from these cases, he should in future adopt similar measures, chiefly relying on the opium, the sedative effects of which, he hoped, would be most effectually obtained, by premising large bleeding, and the use of calomel as a purge. The result of the abovementioned case will substantiate the propriety of the practice. It will be observed, that on the return of the paroxysm, which was slight, the enema, with the tincture of opium, was administered with immediate relief. This circumstance, together with the previous mode of treatment, shows the power of opium as a remedy in this affec. tion, whether exhibited by the mouth or per anum. This, however, and the successful case to which Mr. W. Wickham alluded, proved that no preference need be given to the injection, rather than the opium by the mouth.

Winchester, Aug. 20, 1828.

\section{ST. BARTHOLOMEW'S HOSPITAL.}

FRACTURE OF TIE SKULL, WITH DEPRESSION - REMOVAL OF THE DEPRESSED BONE-HERNIA CEREBRI, AND DEATH.

W. Causton, æt. 9, was admitted Aug. 15. It appeared that the father and the boy had been drinking tea out of a pewter pot; the father became enraged with his son, and threw the pot, and struck him a severe blow on the side of the head; the poor boy fell down; he was not insensible, but, in a few minutes he became sick, and romited. He walked to the hospital; on admission, he was perfectly sensible; his pulse was frequent and feeble. Upon examination, there was a lacerated wound of the scalp, and a portion of the temporal muscle extending above the right ear, for about three inches in length; a considerable portion of the parietal and temporal bones was found fractured, and driven in on the brain; the dura mater was torn through about two inches in length, exposing the brain, small portions of which, mixed with blood, came through the fractured opening. The eleva. tor was applied, and the depressed bone removed, leaving an oval aperture three inches in length, and two in breadth. The integuments were brought together by adhesive straps, and covered with a cold damp cloth. In the evening, there was heat of skin, with a sharp and very frequent pulse; he was bled to twelve ounces, and some aperient medicine was given.

16. Has been in a quiet dozing state during the whole night; he is sensible; tongue natural; bowels open; skin more cool; pulse frequent and sharp; complains of slight pain in the head; has been bled to eight ounces this morning. In the afternoon his pulse again rose, and eight ounces of blood were taken; it was cupped and buffed.

17. Has passed a good night; complains of no pain; the pulse is very frequent and sharp. Venesection ad $\overrightarrow{3}$ viij. Blood inflamed.

19. Is going on farourably; he complains of no pain ; is perfectly sensible ; he has no heat of skin ; tongue natural; and he sleeps well. The pulse, however, still continues frequent, 100, and sharp. The dressings were taken off. The brain was found protruded through the laceration of the dura mater, and somewhat raised above the level of the scalp; it was of a greyish colour, very soft, and there was slight serous discharge from it. Its pulsations were synchronous with those of the heart; the boy manifested no pain nor uneasines, on its being touched or pressed. Adhesive plaster, 